\title{
Die Abraham-motief in Matteus 1-4
}

L Nortjé

(RAU)

\section{ABSTRACT}

The Abraham-motive in Matthew 1-4

Matthew's indication of Jesus as the Son of David and the Son of Abraham develop along two lines in Matthew's story. Firstly, is Jesus portrayed as the Son of David, who represents the "Jewish" line in the story. And secondly Matthew is using Jesus as Son of Abraham to develop the "gentile" line in the story. Marhew uses the Abraham motives in chapters 1-4 10 illustrate the inclusion of the gentiles into the new people of God. Under discussion are the gentile women in the genealogy and other possible motives that reflect the story of Abraham.

\section{INLEIDING}

Vergelykende studies tussen Matteus, Paulus en Jakobus is nog lank nie uitgedien nie. In die sentrum is die vraag na die posisie en geldigheid van die wet vir die christengelowige. Paulus leun swaar op die Abrahamtradisie om sy standpunt oor die einde van die geldigheid van die wet, te steun (vgl Rom 4; 9-11; Gal 3-4). Paulus gebruik die voorbeeld van Abraham, omdat Abraham voor die wet geleef het, en dit Paulus se argument ondersteun het. Jakobus verwys nie na Abraham nie, maar verdedig die blywende geldigheid van die wet. Dit is verstaanbaar dat Matteus wat ook die geldigheid van die wet beklemtoon, nie eintlik veel kere na Abraham verwys nie.

Tog is Jesus as seun van Abraham, klaarblyklik een van die sleutels waarmee die Matteusevangelie verstaan moet word (vgl Matt 1:1,17). Die heilshistoriese benadering het ook ruimskoots van hierdie vertrekpunt gebruikgemaak om Matteus te verklaar'. In hierdie studie gaan gekyk word na 'n paar moontlike Abraham-motiewe in Matteus 1-4 en wat Matteus se bedoeling was om hierdie motiewe in te sluit.

\section{IIEIDENSE VROUE IN DIE GESLAGREGISTER}

\subsection{Die heidense vroue as karakters ${ }^{2}$}

Nieteenstaande die Matteusevangelie se oorwegend Joodse karakter, het die heidene ' $n$ betekenisvolle plek in die verhaal. Matteus reflekteer 
verskeie groeperinge van heidene. Eerstens is daar die heidene wat as ongelowiges en nie-Jode bestempel kan word, byvoorbeeld Matteus 5:47, $6: 7,32$. Tweedens is daar die gelowiges in die Matteusgemeenskap wat waarskynlik van heidense afkoms is. Dit word gerugsteun deur die debat rondom die identiteit van die outeur; die skerp veroordeling van die Fariseërs en die Joodse leiers; die verwerping van Israel en die inneem van die plek van Israel deur die heidene (Matt 21:43); die vestiging van 'n nuwe volk van God, naamlik die Kerk (Matt 18) en die uiteindelike missie van die Kerk wat op die heidene gerig is (Matt 28:19)3.

Die derde groep wat ek wil onderskei is die heidense vroue. Matteus se vermelding van hierdie vroue val nie in bogenoemde kategorië nie. Uit die aard van hulle oorspronklike konteks is hulle wel ongelowige heidene, maar nie in die sin van die ander heidene waarna Matteus verwys nie. Die karakterisering van hierdie vroue figure, soos die ander figure in die verhaal, word gedoen ten opsigte van die protagonis, Jesus. As karakters figureer hulle, soos die skares, langs twee lyne: As heidene dien hulle as "foils" vir die dissipels en is deel van die antagoniste, maar hulle "geloof" verander hulle van ondersteuners van die antagoniste na volgelinge en ondersteuners van Jesus. Hulle beïnvloed nie die plot of vloei van die verhaal nie. Maar aan die ander kant is hulle nooit vyandig teenoor Jesus nie. Die heidenkarakters ontwikkel nie in die verhaal nie, ten spyte van die feit dat die verhaal met die heidense vroue begin en met die sendingopdrag aan die heidene eindig4.

Matteus het 'n besondere doel gehad waarom hy die heidense vroue in die begin van sy evangelie noem. Buiten dat hy, ongewoon aan die Joodse tradisie, vroue in sy geslagregister insluit, is hulle nog boonop heidense vroue. En indien ons in ag neem hoe sterk Israel gekant was teen huwelike en vermenging met heidense vroue, openbaar die geslagregister die ironie van die saak. Dit gaan in die eerste instansie nie oor die insluiting van hierdie heidense vroue in die geslag van Jesus nie, maar die onthulling van die verbondslyn van Abraham en Dawid.

Jesus egter, as die seun van Abraham en veral die seun van Dawid, is die een wat medelye het met diegene wat deur die geestelike leiers geminag word. Daarom is dit juis betekenisvol dat hierdie vroue in sy geslagslinie ingesluit word. 


\subsection{Tamar}

\subsubsection{Historiese agtergrond:}

Uit Genesis 38 is dit nie duidelik uit watter volk sy afkomstig was nie. Volgens tradisies in die Testament van die Twaalf Patriarge en die Boek van Jubilieë was sy afkomstig van Aram, die land van Abraham, Rebekka, Lea en Ragel. Volgens die verhaal in Genesis, is sy deur Juda gekies om die vrou van sy oudste seun en erfgenaam te wees (Gen 38:6). Maar toe hy sterwe as gevolg van sy lewe van ongeregtigheid, het Onan, die tweede seun wat haar as vrou moes neem, haar verneder deur met haar gemeenskap te hê, maar sy verantwoordelikheid ten opsigte van haar reg op 'n nageslag, nie na te kom nie. Ook Juda ontneem haar van hierdie reg deur nie sy ander seun vir haar as man te gee nie. Haar nie-Kanaänitiese afkoms word in Jubilieë en Testament van die Twaalf Patriage gegee as die rede waarom sy deur Juda se Kanaänitiese vrou en haar seuns verwerp is (T Jud 10; Jub 42:1-7).

Abraham (Gen 24:3-4) en Isak (Gen 28:1) het opdrag aan hulle seuns gegee om nie met Kanaänitiese vroue te trou nie. Deur hierdie opdrag te gehoorsaam verseker hulle dat God se beloftes aan Abraham en Isak gehandhaaf word 5 . As plaasvervanger vir Juda se Kanaänitiese vrou, herstel Tamar die Abrahambeloftes omdat sy net soos Rebekka, Lea en Ragel nie Kanaänities was nie.

Ironies genoeg het Juda daarop aangedring dat sy verbrand moes word vanweë haar hoerery, totdat sy eie ongeregtigheid aan die lig gekom het (Lev 21:9; Gen 38:24). Tamar herstel die onreg wat aan haar gedoen is deur vasbeslote en planmatig haar reg terug te eis. Met haar optrede ontmasker sy die ongeregtigheid van Juda en sy seuns en háár seun word deel van die verbondslinie vir die Messias. Sy as heidense vrou het die verbondslinie instand gehou toe die verbondslede se optrede dit bedreig het. Dit word bevestig in Rut 4:12 waar die leiers in die stadspoorte Rut en Boas se nageslag seën en vergelyk met die nageslag van Tamar en Juda.

\subsubsection{Tamar se narratiewe rol in Matteus 1:3:}

Tamar is die eerste vrou waarna Matteus in sy evangelie verwys. Haar optrede is ' $n$ daad van geregtigheid en deur haar volharding hou sy die Abrahambelofte instand toe dit bedreig word. Die manlike name in die geslagsregister verteenwoordig die Dawidiese lyn, maar die heidense vroue hou die Abrahambelofte instand. Jesus as die seun van Abraham gaan na 
Galilea waar die heidene woon (Matt 4:15) om sy sending te begin. Hierdie sending word aan die einde van die verhaal op die wêreld gerig, die vervulling van God se belofte aan Abraham dat alle nasies deur hom geseën sal word.

\subsection{Ragab}

\subsubsection{Historiese agtergrond}

Ragab was 'n Kanaänitiese prostituut. As 'n Kanaänitiese vrou staan Ragab in kontras met die nie-Kanaänitiese Tamar en die vroeëre nie-Kanaänitiese matriage. In die verhaal in Josua 2 is sy die hoofkarakter. Sy neem die inisiatief en manipuleer die gebeure: Sy versteek die spioene en lei die polisie op 'n dwaalspoor (Jos 2:5,16). Sy onderhandel met die vyand om veiligheid en voortbestaan vir haarself en haar familie te verseker (Jos $2: 12-14)$. Sy eis dat die spioene hulle belofte met 'n eed voor die Here gestand sal doen (Jos 2:12-13). Sy word die beskermer van haar familie. Haar daad verseker nie net die veiligheid van haar familie en almal in haar huishouding nie, maar verseker ook dat sy en haar nageslag in die land van Israel bly woon. Meer nog, sy word deel van die Messiaanse verbondslinie.

\subsubsection{Ragab se narratiewe rol in Matteus 1:5}

Ragab word in die geslagsregister ingevoeg as die eerste voorbeeld van 'n heiden met geloof in die God van Israel. Daar bestaan nie bronne wat meld dat Ragab die moeder van Boas was nie en volgens berekening het sy ten minste 200 jaar voor Boas geleef. Dus kan ons sê dat haar invoeging in die geslagregister van Matteus nie is omdat sy die moeder was van een van die manlike voorgeslagte van die Messias nie ${ }^{6}$.

Matteus wil wys dat hierdie heidense Kanaänitiese vrou se optrede gekoppel word aan die verlossingsdade van God (Jos 2:10). En daarmee 'n inleiding gee op God se finale verlossingsdaad in Jesus die seun van Dawid en seun van Abraham. God se verlossing wat nie net vir die Jode bedoel is nie, maar ook gerig is op die heidene (vgl Matt 28:19). 


\subsection{Rut}

\subsubsection{Historiese agtergrond}

Dit is reeds merkwaardig dat in die Hebreeuse kanon ' $n$ boek opgeneem is wat die verhaal vertel van 'n heidense vrou en wat ook haar naam dra. Die rede is waarskynlik dat sy, 'n Moabitiese vrou, haar verbind het met Israel en die God van Israel. Na die dood van haar Joodse man, word Rut deur haar skoonmoeder aangeraai om na haar land en haar gode terug te keer. Maar Rut verkies vasbeslote om die onbekende (Rut 2:11) aan te durf, ter wille van haar geloof (Rut 1:18).

Rut se optrede, soos die van Ragab, is berekenend. In die verhaal ontwikkel Rut se karakter van 'n gehoorsame en gedienstige vrou na die van 'n vrou wat berekend optree om haar doel te bereik, na 'n vrou wat deur die leiers van die volk geseën word tot die ouma-grootjie van koning David. Dit het nie sonder meer gebeur nie. Sy moes deur hierdie hele proses gaan om te verseker dat reg aan haar en haar skoonmoeder geskied. Die onreg wat Rut in die gesig gestaar het, is dat sy as heidense vrou nie in aanmerking sou kom vir die leviraatshuwelik nie. Toe Boas die lossingsreg oorneem, die stuk grond koop en Rut as vrou neem, kon Rut haar regmatige plek inneem. Rut het saam met Ragel en Lea gebou aan die volk Israel (Rut $4: 11$ ). "The action of the woman is associated with the action of God"7.

\subsubsection{Rut se narratiewe rol in Matteus 1:5}

Die verskyning van die naam van Rut in die geslagregister is weer eens ' $n$ toevoeging van Matteus. Binne die konteks van die geslagsregister, voeg Matteus haar nie in om haar goeie hoedanighede te beklemtoon nie, maar gaan dit oor haar keuse vir die God van Israel (Rut 2:12). Daarmee het sy, deur haar skoonmoeder te volg, op haar regte as kinderlose weduwee aanspraak gemaak.

Matteus wil weer eens 'n heidense vrou voorhou as ' $n$ voorbeeld van iemand wie se optrede volgens die wil van God is, 'n vrou wie se dade geassosieer word met die dade van God. Rut en Ragab se optrede herinner aan die optrede van Abraham, wat sy land en volk verlaat het om die onbekende met God aan te durf.

Tamar, Ragab en Rut word sterk met die Abrahamtradisie geassosieer. Wanneer die belofte gevaar loop om vernietig te word as gevolg van die manlike draers se sonde en ongeregtigheid, dien hulle as beskermers van die belofte van God aan Abraham. 


\subsection{Die vrou van Urija}

\subsection{Historiese agtergrond}

Matteus verwys na hierdie vrou as die vrou van Urija. Uit 2 Samuel 11:3 weet ons dat haar naam Batseba, die dogter van Eliam, die vrou van Urija die Hetiet, was. In 2 Samuel 11-12 word deurgans na haar verwys as die vrou van Urija. Selfs nadat Urija gesneuwel het en Dawid haar as sy vrou geneem het (2 Sam 11:27). Dit is eers met die dood van die kind wat in ongeregtigheid verwek is, wat sy Batseba genoem word (2 Sam 12:24). En dit is as Batseba, die vrou van Dawid, wat sy die moeder van Salomo geword het en sy 'n plek in die Dawidiese en dus die Messiaanse linie verkry het.

In die verhaal in 2 Samuel 11-12 speel sy 'n passiewe rol. Nooit kom sy aan die woord of word haar optrede aktief beskryf nie. Uit 1 Konings 1:11-13 en 28-31 is dit tog duidelik dat Batseba se optrede berekend was. Hierdie verse verwys na 'n belofte wat Dawid aan haar gemaak het dat haar seun Salomo na hom koning sou word. Daarmee het sy vir haarself en haar seun 'n toekoms verseker: hy as koning en sy as koningsmoeder. Daarsonder sou hulle waarskynlik doodgemaak word (1 Kon 1:12). Maar daarmee word ook verseker dat die nageslag van die sondige Saul (Dawid se kinders by Saul se dogters) nie die koningskap verkry nie.

In die vroeë rabbynse tradisie word Batseba geassosieer met die "devine guidance of Israel's unfolding history and with the action of God"8.

\subsubsection{Die vrou van Urija se narratiewe rol in Matteus 1:6}

Matteus verswyg doelbewus die vrou se naam, omdat hy sy lesers nie wil herinner aan die moeder van Salomo nie, maar aan die sonde en ongeregtigheid wat Dawid gepleeg het. Alhoewel Urija die Hetiet, 'n heiden was, is die Here ook die beskermer van sy regte en sal onreg wat aan hom gedoen is, ook gestraf word. In 2 Samuel 12:10 sê die Here vir Dawid: "Daarom sal die swaard nou nooit meer uit jou huis weggaan nie, want jy het my geminag". Die sonde wat deur Juda begin is, geïntensifiseer is deur Dawid en voortgesit is deur sy nageslag, het 'n hoogtepunt bereik met die Babiloniese ballingskap (Matt 1:11) .

Matteus se vermelding van die vrou van Urija roep ook in herinnering die oordeel van Natan oor Dawid se sonde omdat hy die Here geminag het (2 Sam 11:10). Die implikasie hiervan is dat elkeen wat die Here 
minag ook die oordeel van Natan oor hulleself voltrek. Hulle wat hulleself die kinders van Abraham noem, en dink dat hulle nie die bekering nodig het nie (Matt 3:7-12), maar verantwoordelik is vir die dood van die regverdiges en onskuldiges, dieselfde oordeel sal hulle tref (Matt 23:29-36).

Met die insluiting van die naam van die vrou van Urija, die Hetiet in die geslagregister, blyk dit dat die belofte aan Abraham en dié aan Dawid bymekaar aansluit. Daar word ook nie weer na 'n vrou verwys, voor die vermelding van Maria, die moeder van Jesus nie.

\subsection{Gevolgtrekking}

Uit bogenoemde analise van Matteus se gebruik van die heidense vroue karakters in die geslagregister, kan afgelei word dat hierdie vroue die instandhouers van die Abrahambelofte is. Soos Abraham verteenwoordig hulle heidene wat deur God geroep is en wat in geloof geantwoord en gereageer het op God se roepstem, al het dit radikale implikasies vir hulle en hulle families beteken.

\section{ANDER MOONTLIKE ABRAHAM-MOTIEWE IN MATTEUS 1-4}

\subsection{Die Josefverhaal: Matteus 1:20-21}

Die Abraham-motief word ook in die Josefverhaal gereflekteer. Beide figure staan aan die begin van 'n nuwe fase. Hulle kry hulle opdragte direk van God deur middel van drome en reageer in gehoorsaamheid. In Genesis 15 sluit God met Abraham die verbond wat 'n groot invloed op die lewe en geskiedenis van Israel sou hê. Hy doen dit grotendeels deur 'n gesig (Gen 15:1) en 'n droom (Gen 15:12 ev).

Matteus is die enigste evangelie waar goddelike bevele deur drome bekend gemaak word. In Handelinge 16:9 en 18:9 word opdragte aan Paulus gegee deur middel van gesigte of visioene. Die openbaring aan Johannes word ook in 'n gesig of visioen gegee (vgl Op 1:1) ${ }^{10}$. In Matteus word daar ses keer na drome verwys. Hoofsaaklik in Matteus 1-2 en dan aan die einde van die verhaal in Matteus 27:19. Die eerste gebruikmaking is in Matteus 1:20 waar God aan Josef bekend maak dat Maria se swangerskap van die Heilige Gees is. Dit bevestig die goddelike oorsprong van die ontvangenis. Net soos by God se verbondsluiting met Abraham, is die geboorte van Jesus nie deur mense bewerkstellig of bedink nie.

In beide gevalle bevat die drome 'n goddelike belofte"l. In Genesis 15:4,5 en 18 beloof God aan Abraham dat $\mathrm{Hy}$ aan hom 'n groot nageslag 
sal gee en hierdie land om in te woon. In Matteus 1:20-21 sê God aan Josef met betrekking tot Jesus dat dit $\mathrm{Hy}$ is "wat sy volk van hulle sondes sal verlos".

\subsection{Die Magi: Matteus 2:12}

Merkwaardig genoeg word ook die heidense magi wat hulle land verlaat het en na Israel gereis het, deur God gewaarsku om sodoende hulle lewe te beskerm. Die heidense afkoms en die land waarvandaan hulle gekom het is hier van belang. Hulle was net soos Abraham heidene en was afkomstig van die Ooste waarvandaan Abraham ook gekom het. Abraham het na die Suide getrek op God se bevel en die magi het die sterreverskynsel aan die hemelruim gevolg. Dit was vir albei onbekende bestemmings wat hulle aangedurf het.

\subsection{Die vlug na Egipte: Matteus 2:13, 19-20}

Abraham moes volgens Genesis 12:10 na Egipte gaan om 'n heenkome te vind vanweë 'n baie swaar hongersnood in Kanaän. Sy verblyf in Egipte was waarskynlik van korte duur. Dit is tog merkwaardig dat die "Egipte"gebeure in Genesis en Matteus aan die begin van die verhaal van Abraham en van Jesus voorkom en dat beide se verblyf van korte duur en sonder enige betekenis was.

Die meeste geleerdes sien hier 'n verwysing na die Eksodusverhaal. Dit word ondersteun deur die Skrifaanhaling uit Hosea 11:1. Wat wel in die guns van 'n Abraham-analogie tel, is dat Jesus in Matteus 1:1 die seun van Abraham genoem word'2.

\subsection{Ragel se kinders: Matteus 2:17}

Dit is merkwaardig dat Matteus Jeremia 31:15 as vervullingsitaat gebruik vir die kindermoord deur Herodes. In Jeremia dui dit op die terugkeer van die ballinge na die beloofde land. Die kinderlose Ragel huil oor haar "kinders" Israel wat nie meer in hulle land is nie. Matteus gebruik die verwysing om na die vermoorde kinders te verwys. Dit is nie duidelik wat Matteus se motief met hierdie aanhaling was nie. Dit lyk of dit eintlik buite konteks aangewend is. Ook hierdie aanhaling herinner aan die Abrahamverhaal.

Keil en Delitzsch het ' $n$ interessante opmerking, naamlik dat Ragel gesien moet word as die gemeenskaplike moeder van die verlore Israeliete 
en die vermoorde kinders. Sy is die geliefde vrou van Jakob wat gedurende haar leeftyd vurig verlang het na kinders. Net soos die volk van Israel dikwels bekend gestaan het onder die benaming "dogter van Sion", as hulle ideale verteenwoordiger, so word die groot matriarg van Efraim, Benjamin en Manasse hier genoem as die verteenwoordiger van die matriargale liefde wat deur Israel getoon word wanneer daar getreur word oor die verlore volk ${ }^{13}$. In die konteks van Matteus 1-2 kan dit ook dui op die verwerping van Israel, omdat die doodmaak van die kinders juis gerig was op die vernietiging die ware Koning en Verlosser van die Jode.

\subsection{Johannes die Doper se prediking: Matteus 3:9}

Behalwe aan die begin van die evangelie word daar in Matteus net drie keer na Abraham verwys: 3:9, 8:11 en 22:32. Hierdie verwysings kom almal uit Q. Catchpole ${ }^{14}$ meen dat die hipotetiese uitspraak "Ons het Abraham as voorvader", betrekking het op enigiemand in Israel en nie net op 'n sekere groep skynheiliges, Fariseërs en Sadduseërs nie. Almal in Israel het Abraham as voorvader, maar die tyd dat dit hulle toegang gegee het tot God se verbondsbeloftes is verby. In Matteus 7:21 geld dieselfde beginsel vir die lede van die Kerk, wanneer Jesus sê: “Nie elkeen wat vir My sê: 'Here, Here', sal in die koninkryk van die hemel ingaan nie, maar net hy wat die wil doen van my Vader wat in die hemel is". Jesus lê self die vereiste neer waaraan Jood en nie-Jood moet voldoen, naamlik, om die wil van God te doen.

Hieraan het die Fariseërs en Sadduseërs nie voldoen nie. Daarom word die verwysing na Abraham telkemale gebruik om die veroordeling en verwerping van die geestelike leiers van Israel aan te dui. Hulle afstamming dien vir hulle genoeg sekuriteit om kinders van God te wees. Die oordeel wat Johannes in verse 10-12 uitspreek, dui op die verwerping van die leiers as die nageslag en dus as die verbondsdraers van Abraham. In Matteus 8:11-12 word hierdie verwerping nog duideliker uitgedruk: "Baie sal van die Ooste en die Weste af kom en saam met Abraham, Isak en Jakob aan tafel gaan in die koninkryk van die hemel. Maar mense vir wie die koninkryk bedoel is, sal in die diepste duisternis daarbuite gegooi word, waar hulle sal huil en op hulle tande sal kners".

Met hierdie gedeeltes inaggenome, blyk dit dat Matteus daarmee wil aandui dat ' $n$ ander volk, wat die heidene insluit die nuwe nageslag van Abraham sal wees. 


\subsection{Die eerste optrede van Jesus: Matteus 4:15-16}

Jesus begin sy optrede in Galilea. Matteus ondersteun sy verskuiwing van Nasaret na Kapernaum met 'n vervullingsitaat uit Jesaja 8:23-9:2. Galilea word in die aanhaling aangedui as die plek waar die heidene woon. Matteus wysig die Skrifgedeelte om sy saak te ondersteun. In Jesaja word Galilea nie aangedui as die gebied van die heidene nie. Volgens Jesaja lyk dit of hier van twee gebiede gepraat word: Galilea, die Jordaanstreek en die gebied van die heidene. Matteus indentifiseer doelbewus Galilea en die gebied van die heidene met mekaar om Jesus se bediening aan die heidene te beklemtoon.

Die Ou Testament aanhaling ondersteun Jesus se sending aan die heidene. Dit is in Galilea wat die opgestane Heer die opdrag aan die dissipels gee om dissipels van al die nasies te maak (Matt 28:16-20). Dit alles geskied in ooreenstemming met die wil en plan van God. Dit is Jesus se uiteindelike doel. Nadat hierdie sendingsdoel van Jesus met die Skrifaanhaling bekend gemaak is, het Hy in vers 17 met sy prediking aan Israel begin. Dit is vir Matteus belangrik dat die sending aan die heidene 'n bybelse, profetiese perspektief het ${ }^{15}$.

\section{GEVOLGTREKKING}

Uit bogenoemde analise blyk dit dat Matteus die Abraham-motiewe in hoofstuk 1-4 gebruik om die insluiting van die heidene by die nuwe volk van God, aan te dui. Die heidense vroue in die geslagregister verseker telkemale dat die belofte van God aan Abraham instand gehou word, wanneer die optrede van die draers van hierdie verbond dit in gevaar stel. Selfs die begin van die Jesusverhaal het analogië met die Abrahamverhaal, wanneer God met Abraham en Josef deur middel van drome kommunikeer. Dit is merkwaardig dat aan die einde van die verhaal ontvang die vrou van Pilatus ook 'n waarskuwing in 'n droom in verband met Jesus.

Matteus sluit sy evangelie af met Jesus se sendingopdrag aan die dissipels om die evangelie aan al die nasies te verkondig. Hiermee gee hy aan die evangelie 'n definitiewe universele karakter.

Uit bogenoemde bespreking, blyk dit dat Matteus se aanduiding van Jesus as seun van Dawid en seun van Abraham, langs twee lyne in die verhaal ontwikkel. Die eerste is Jesus as die seun van Dawid, wat die "Joodse" lyn in die verhaal uitbeeld. Tweedens, gebruik Matteus Jesus as seun van Abraham om die "heidense" lyn te ontwikkel en uit te beeld. Hierdie motief kan ook aan die res van die verhaal getoets word. Indien 
Matteus wel Abraham gebruik om die heidense gelowiges aan te dui en uit te beeld, beteken dit dat Matteus ook soos Paulus, Abraham gebruik om die insluiting van die heidene in die volk van God, aan te dui. Tog verskil Matteus se motief en aksent hemelsbreed van dié van Paulus.

Die implikasie van die gevolgtrekking is dat Matteus doelbewus sy evangelie so gekomponeer het, om sodoende die twee aspekte van die Kerk uit te beeld en dat hy die sleutel vir die verstaan daarvan in Matteus 1:1 aandui.

\section{NOTAS:}

1 D R Bauer, The structure of Matrhew's Gospel. A study in literary design, Sheffield 1989, 45-55.

2 L Nortjé, Gentile female characters in Matthew's story: An illustration of righteousness, Leiden 1998 (In druk).

3 S Van Tilborg, The Jewish leaders in Marthew, Leiden 1972, 171-172.

4 J D Kingsbury, Matthew as Story, Philadelphia 1988, 18.

5 J P Heil, "The Narrative Roles of the Women in Matthew's Genealogy", Biblica 72 (1991), 539.

6 E M Wainwright, Towards a feminist critical reading of the Gospel according to Matthew, Berlin 1991, 166.

$7 \quad$ Wainwright, $a w, 168$.

8 Aanduidings hiervan word moontlik gevind in b.Sanh 101a; Midr Ps 3:5; b.Sanh 107a, Wainwright, $a w, 1991,169$.

9 Heil, $a w, 541-542$.

$10 \mathrm{R} \mathrm{K}$ Gnuse, The dream Theophany. Its structure in relation to ancient Near Eastern dreains and its theological significance, Lanham 1984, 11.

11 Gnuse, $a w, 65$.

12 U Luz, Matrhew 1-7. A commentary (translated by Linss), WC Minneapolis $1989,148$.

13 C F Keil \& F Delitzsch,. Commentary on the Old Testament in ren volumes. Volume VIIl: Jeremiah, Lamentations, Grand Rapids 1980, 25.

14 D R Catchpole, The quest for $Q$, Edinburgh 1993, 8.

$15 \quad$ Luz, $a w, 195$. 